\title{
Experimental Study and Numerical Simulation of the Reinforced Concrete Walls with Different Stirrup in the Boundary Element
}

\author{
Hongmei Zhang ${ }^{1}$, Xilin $\mathrm{Lu}^{*^{2}}$ and Xiaohan $\mathrm{Wu}^{3}$ \\ ${ }^{1}$ Lecturer, State Key Lab. of Disaster Reduction in Civil Engineering, Tongji University, China \\ ${ }^{2}$ Professor, State Key Lab. of Disaster Reduction in Civil Engineering, Tongji University, China \\ ${ }^{3}$ Associate Professor, State Key Lab. of Disaster Reduction in Civil Engineering, Tongji University, China
}

\begin{abstract}
Reinforced concrete shear wall is one of the main lateral resistance members in tall buildings. A further understanding of shear walls is believed important to the seismic design. To day, it is recognized that boundary elements will contribute to the seismic behavior of shear walls, though the extent still remains vague and evidence is seldom given by relative experiment. Further-more, the nonlinear capacity evaluation method of shear walls is also a difficulty, especially considering the boundary elements. This paper aims to extend the relevant existing studies with the following two programs: (1) The experimental study of shear walls with different stirrup ratios in boundary areas; (2) A numerical simulation study of the three specimens. A finite element program SAPCAD is applied to simulate the seismic behavior of the shear wall specimens with different boundary condition. The experimental study and the numerical simulation in this paper indicate that: (1) A properly distributed boundary element may be helpful to avoid local crush and brittle failure; (2) The lateral load-carrying capacity could be influenced by stirrup bars; (3) The cyclical load simulation results drawn by SAPCAD agree with the test results. And some of the stirrup effect could be evaluated by this kind of simulation.
\end{abstract}

Keywords: cyclic loading experiment; shear wall; boundary element; finite element program; numerical simulation

\section{Introduction}

Reinforced concrete shear wall is the main structure member to offer great potential for both lateral load resistance and drift control. While the current shear wall design faces several uncertainties: Behavior of the wall with different boundary stirrup shows great complexity and how to arrange or simulate the effect of the stirrup at wall boundary still remains unclear ${ }^{1)}$. Current theories and experiences show that the boundary element will greatly influence the seismic behaviors such as the ductility, the rigidity, and the lateral resistance capacity of the shear walls. When the shear wall is under a small eccentric compression condition, the ductility will be deteriorated. Even if it is under a large eccentric compression condition, there will be high stress at the boundary of the wall. If the boundary is not sufficiently confined, the boundary concrete will first reach its ultimate compression strain.

*Contact Author: Xilin Lu, Professor, Tongji University, Research Institute of Structural Engineering and Disaster Reduction, Tongji University, Shanghai, 200092 China Tel: +86-21-65984945 Fax: +86-21-65984945

E-mail: 1xlst@tongji.edu.cn

( Received October 8, 2009 ; accepted May 27, 2010)
Recent research work showed that enough and properly arranged stirrup in the boundary area could confine the core concrete and the longitudinal reinforcement efficiently in the boundary area. Exist theory believe that the boundary element could help to avoid a brittle mode and enhance carrying capacity. The lateral bearing capacity is related to the triaxial compression condition. And the strength of the concrete could develop at the compression area and the effect will be more apparent in the compression area ${ }^{1)}$. The lateral stirrup of the confined shear wall members has three main effects: a) provide shear-carrying capacity of the diagonal section; b) constrain the core concrete, and increase the ultimate compress strain limit to prove the rotation capacity of the section in the plastic area; c) prevent the longitudinal reinforcement at the edge from buckling too early. In most cases, the ultimate compression of the unconfined concrete could not confirm the plastic area reach its prescribed rotational capacity.

The stirrup ratio at the boundary area influences the seismic behavior of the wall. However, it has not been evidenced by convincing experiments, and the role of the character value of stirrup on shearing resistance still remains vague. The method of providing a rather precise simulation result of the shear wall considering 
the boundary stirrup is still need investigation.

This paper is intended to a) verify experimentally the validity of the relative analytical findings, and b) give a simulation method considering the influence of the boundary stirrup ratio.

\section{Experimental Program}

To find the influence of the boundary stirrup ratio on the reinforced concrete shear walls, four specimens of reinforced concrete shear wall with different boundary elements were made and tested under reversed cyclic loading. These four specimens were divided into two groups. Each group was tested in the same conditions and was different in the stirrup value. Details of each group are listed in Table 1. and Fig.1. can be found at the boundary stirrup ratio.

\subsection{Material properties}

Material properties are shown in Table 3. and Table 4. which are tested according to Testing Methods for Normal Concrete Mechanical Properties (Chinese code for concrete mechanical property test). All tests were carried out at the State Key Laboratory for Disaster Reduction in Civil Engineering in Tongji University.

\subsection{Testing procedure and loading sequence}

Each specimen was subjected to a combination of axial and horizontal loading using the testing rig shown in Fig.2. The axial load was first applied by 3 hydraulic jacks and was adjusted during the test to maintain the vertical load at a constant value. The horizontal load was applied by a hydraulic actuator which

Table 1. Parameter Details of the Specimens

\begin{tabular}{|c|c|c|c|c|c|c|c|c|}
\hline Group & $\begin{array}{l}\text { Specimen } \\
\text { Number }\end{array}$ & $\begin{array}{l}\text { Boundary } \\
\text { Stirrup }\end{array}$ & $\begin{array}{l}\text { Section Dimension }(\mathrm{mm}) \\
(\text { height } \times \text { width } \times \text { thick })\end{array}$ & $\begin{array}{l}\text { Aspect } \\
\text { Ratio }\end{array}$ & $\begin{array}{l}\text { Concrete } \\
\text { Grade }\end{array}$ & $\begin{array}{c}\text { Constrain Length } \\
\text { (hw is wall } \\
\text { length) }\end{array}$ & $\begin{array}{c}\text { Axial } \\
\text { Compression } \\
\text { Ratio } \\
\end{array}$ & $\begin{array}{c}\text { Longitudinal } \\
\text { Reinforcement } \\
\text { at Confined Area }\end{array}$ \\
\hline \multirow{2}{*}{$\begin{array}{l}\text { Group } \\
\text { I }\end{array}$} & SW6-1 & ф4@80 & $2000 \times 1000 \times 125$ & 2.0 & $\mathrm{C} 40$ & $200\left(0.2 \mathrm{~h}_{\mathrm{w}}\right)$ & 0.30 & $6 \Phi 10$ \\
\hline & SW6-3 & $\phi 6 @ 60$ & $2000 \times 1000 \times 125$ & 2.0 & $\mathrm{C} 40$ & $200\left(0.2 \mathrm{~h}_{\mathrm{w}}\right)$ & 0.30 & $6 \Phi 10$ \\
\hline \multirow{2}{*}{$\begin{array}{l}\text { Group } \\
\text { II }\end{array}$} & SW-2 & ф4@@83 & $1600 \times 850 \times 125$ & 1.88 & $\mathrm{C} 30$ & $188\left(0.22 \mathrm{~h}_{\mathrm{w}}\right)$ & 0.16 & $4 \Phi 10$ \\
\hline & SW-3 & $\phi 6 @ 63$ & $1600 \times 850 \times 125$ & 1.88 & $\mathrm{C} 30$ & $188\left(0.22 \mathrm{~h}_{\mathrm{w}}\right)$ & 0.16 & $4 \Phi 10$ \\
\hline
\end{tabular}

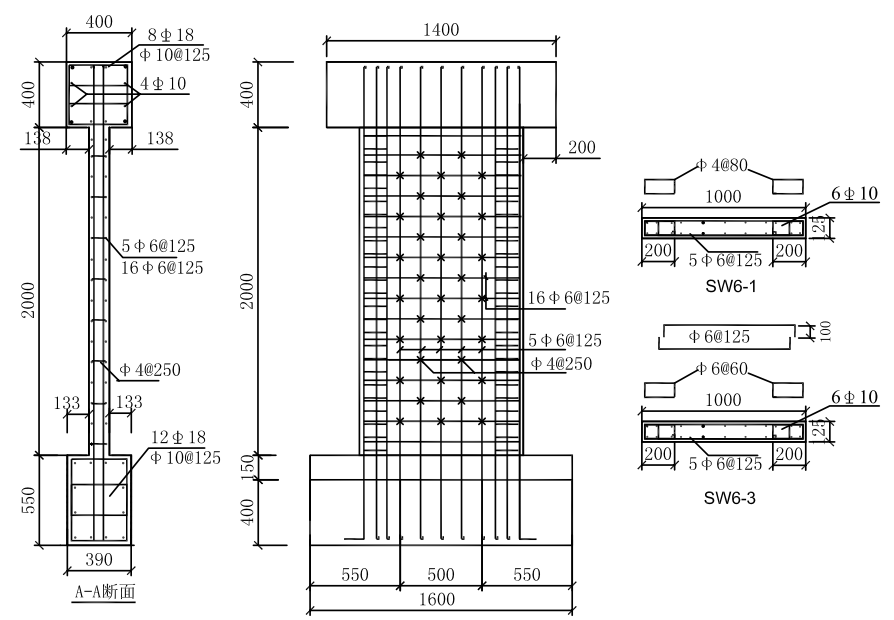

Reinforcement Details of SW6-1 and SW6-3

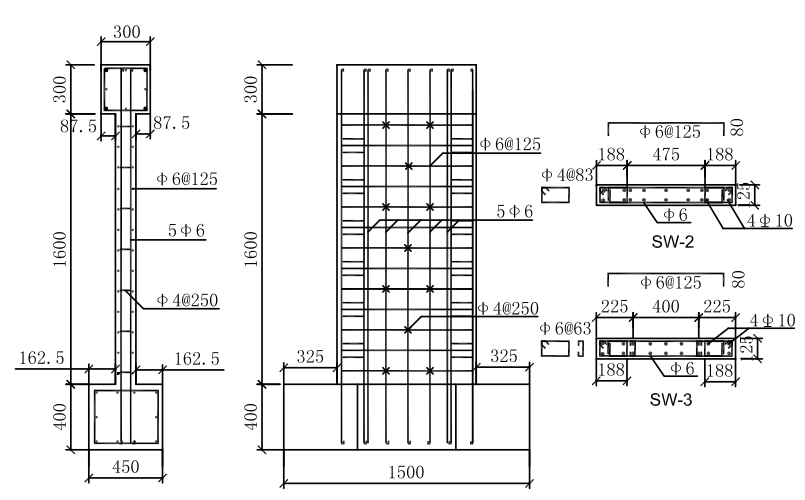

Reinforcement Details of SW-2 and SW-3

Fig.1. Reinforcement Details of SW6-1, SW6-2, SW-2, and SW-3

The experimental work described below involves the details of the four specimens with different boundary element, the testing procedure and the test result. Relative details of the experiment could also be acquired $\mathrm{in}^{2), 3)}$. Attention focused on the lateral resistance capacity, the failure modes and other seismic behavior of the three specimens.

\subsection{Specimen design}

Details of the three $1 / 2$ scale specimens are listed in Table 1. All the four rectangular specimens were tested under reversed cyclic load. Fig.1. shows the nominal dimensions of the four specimens (SW6-1, SW6-3, SW-2 and SW-3) and the boundary reinforcement details. Horizontal and vertical reinforcement of the four specimens is distributed at $\phi 6 @ 125$. Difference was fixed on the concrete reaction wall. Specimens were instrumented with Linear Variable Differential Transducers (LVDTs) for displacement measuring. Electric resistance strain gauges were placed on the reinforcing bars, the surface of the concrete wall and the steel plates to measure the strains. The related instrumentations, including the load cells and the stroke of actuators were connected to data acquisition systems for data processing.

All the four specimens were tested under reversed cyclic quasi-static load. A mixed loading mode was applied in the test. Each test was first conducted under load control until specimen yield, and then continued with a displacement-controlled scheme. The axial load ratio was defined as the vertical load to the concrete 
normal strength of the wall cross section. This load level might represent that of the wall of a mediumheight building. After the axial load was applied, the specimen was incrementally loaded in the horizontal direction. First, the load increment was controlled by 5 or $10 \mathrm{kN}$, when the specimen become yield, the load increment was controlled by displacement and each step was increased by $2 \mathrm{~mm}$. Every load stage was maintained for 3 cycles until the specimen failed. Pressure transducers in the hydraulic supply line of the rams provided the means of accurate measurement of the applied load. Deformation response was monitored by LVDTs calibrated before each test. Three LVDTs were positioned at selected wall elevations to monitor the displacements of the foundation, the middle height and the top beam. Strain gages were employed to measure the steel strains of the longitudinal reinforcing bars at the corner and the center of the specimen.

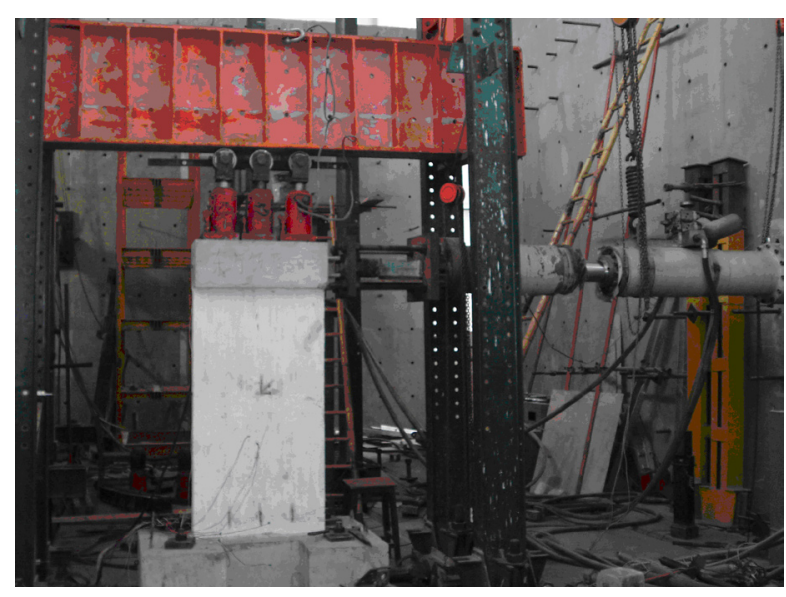

\section{Test Results}

\subsection{The main results}

The test results include the failure modes, the hysteretic loop curve, the scattering of the crack and the rigidity degradation. Main information is given in Table 5. and Fig.3. The behavior in significant stages such as initial cracking, first yield and ultimate is exhibited by Table 5. The top horizontal displacement of the specimens at the top edge of the wall corresponding to:

(1) Initiation of cracking;

(2) First yield of the tensile reinforcement;

(3) Ultimate limit state.

\subsection{Test Result}

The test results could be summarized though the data gathered from the instrument and the seismic behavior property could be drawn by it.

(1) Damage mode. The specimen with lower stirrup ratio was damaged severely at the wall corner and the crack of the specimen with higher stirrup ratio has a more dispersed scatter mode which helps the

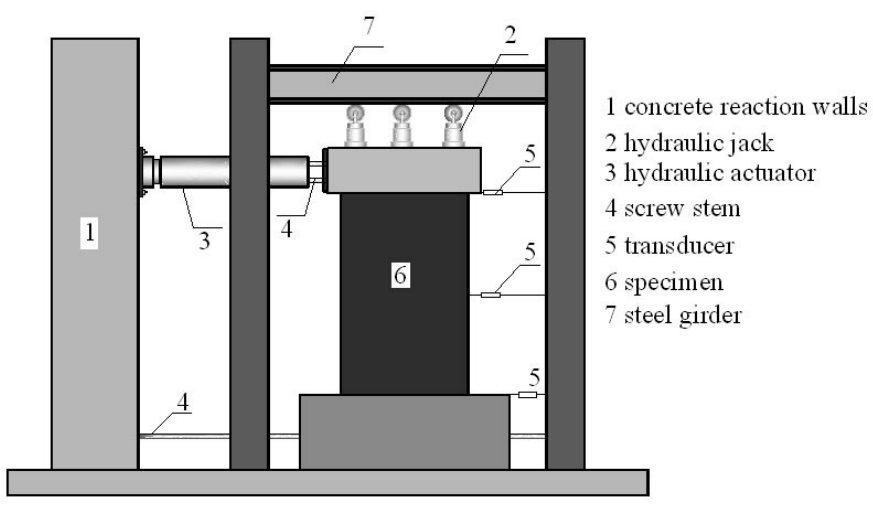

Fig.2. Schematic Representation of the Test Rig

Table 3. Properties of the Concrete

\begin{tabular}{cccc}
\hline Specimen & Uniaxial Compressive Strength/MPa & Cube Crushing Strength/MPa & Concrete Normal Strength/MPa \\
\hline SW6-1, SW6-3 & 30.8 & 37.7 & 37.52 \\
\hline SW-2, SW-3 & 26.46 & 34.33 & 32.61 \\
\hline
\end{tabular}

Table 4. Properties of the Reinforcement Bars

\begin{tabular}{cccc}
\hline Type & Yield Strength $/ \mathrm{MPa}$ & Ultimate Strength $/ \mathrm{MPa}$ & Young's Modulus N/mm \\
\hline D $\phi 6$ & 299 & 411 & $2.19 \times 10^{5}$ \\
\hline D $\phi 10$ & 352 & 505 & $1.769 \times 10^{5}$ \\
\hline
\end{tabular}

Table 5. Experimental Result of the Walls Tested in the Program

\begin{tabular}{|c|c|c|c|c|c|c|c|c|c|}
\hline Specimen & $\begin{array}{l}\text { Boundary } \\
\text { Stirrup }\end{array}$ & $\begin{array}{l}\text { Aspect } \\
\text { Ratio }\end{array}$ & $\begin{array}{c}\text { Axial } \\
\text { Compression } \\
\text { Ratio }\end{array}$ & $\begin{array}{c}\text { First Yield } \\
\text { Drift } \\
\mathrm{P}_{\mathrm{y}}(\mathrm{kN})\end{array}$ & $\begin{array}{c}\text { First Yield } \\
\text { Drift } \\
\Delta \mathrm{Y}(\mathrm{Mm})\end{array}$ & $\begin{array}{c}\text { Maximum } \\
\text { Load } \\
\mathrm{P}_{\mathrm{u}}(\mathrm{kN}) \\
\end{array}$ & $\begin{array}{c}\text { Ultimate } \\
\text { Load } \\
0.85 \mathrm{P}_{\mathrm{u}}(\mathrm{kN})\end{array}$ & $\begin{array}{c}\text { Ultimate } \\
\text { Drift } \\
\Delta \mathrm{U}(\mathrm{mm})\end{array}$ & $\begin{array}{c}\text { Drift } \\
\text { Ductility } \\
\mu\end{array}$ \\
\hline SW6-1 & ф4@80 & 2.00 & 0.3 & 230 & 7.2 & 266 & 226 & 16.9 & 2.3 \\
\hline SW6-3 & ф6@60 & 2.00 & 0.3 & 241 & 7.3 & 290 & 275 & 21.5 & 2.9 \\
\hline SW-2 & ф4@83 & 1.88 & 0.16 & 117 & 9.7 & 151 & 128 & 35.5 & 3.7 \\
\hline SW-3 & ф6@63 & 1.88 & 0.16 & 128 & 10.0 & 166 & 141 & 36.3 & 3.6 \\
\hline
\end{tabular}

*Note: Initiation of cracking, First yield and Ultimate load all mean the lateral load, the yield point defined as the cross point related to the secant line of the $75 \%$ peak strength; related length of plastic area means the ratio of the length of plastic area to the specimen height. 

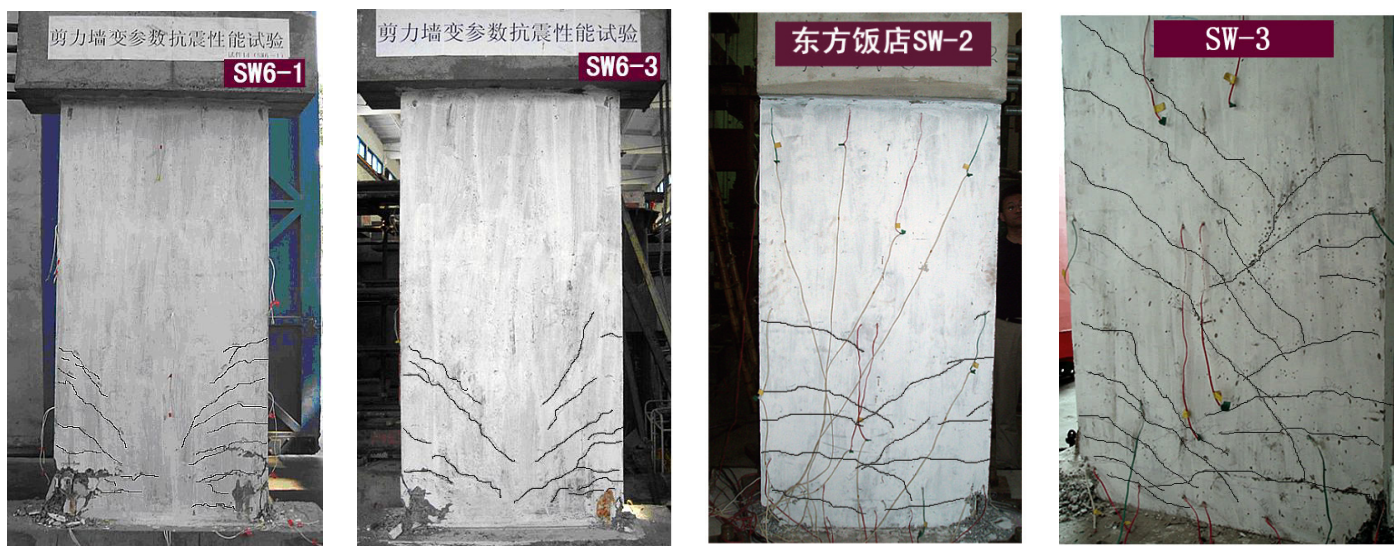

Fig.3. Crack Scattering of the Specimens

specimen to disperse more energy.

(2) Bearing capacity. The specimen with higher boundary stirrup has a higher bearing capacity especially after it is yield. The top-drift skeleton curve could be seen in Fig.4.

(3) Rigidity development. The rigidity degrading curve is shown in Fig.5. Both the two groups of specimens show that the rigidity degrading curve of the specimen with higher boundary stirrup ratio looks gentler. That may indicate higher boundary stirrup could prevent rigidity from degrading.

\section{Experiments Simulation}

As a popular theory, the strain of the shear wall section meets the plane section assumption under a horizontal and vertical load. The longitudinal bar at the outer edge of the section becomes buckled when the wall become yield. And the strain of the outer edge concrete reaches 0.0033 and the wall reaches its ultimate capacity.

The outer concrete of the confined area is crushed when the outer concrete in the plastic area reaches its crush strain. If the core concrete is not confined efficiently, the vertical crack will extend to the core area, and the core area concrete will expand until crushed. If the axial force ratio is high enough, the extension of the vertical crack will also cause the buckling of the longitudinal reinforcement. The lateral stirrup is almost in freely state when the vertical compress is ignored, and the stress of the core area concrete is near to homotaxial strength when the compression is high enough. And the inner crack will develop gradually. The lateral strain will increase at the same time which will promote the lateral stirrup coming into a tension state. Thus the core area concrete could be confined. Lateral stirrup could limit the expansion of the core concrete, so as to increase the concrete ultimate strength and prevent the longitudinal reinforcement from buckling. In fact, it is analytically demonstrated that the lateral resistance is influenced by the reinforcement ratio in the boundary area, which may attribute to the compressive zone when the bending moment develops.
The strain distribution of a wall section is shown in Fig.6. when it is under vertical and lateral load. If the boundary element is appropriately set, the strain development of the concrete will be confined so as to prevent the material from an early crush. If it is confined to a certain value, the boundary element will reduce the relative depth of the compressive zone of the concrete section when it reaches the ultimate state which is showed in Fig.6. It is commonly believed that the ductility of the element will also be improved in this way.

In order to gain a precise evaluation of the seismic behavior of the walls with different boundary elements, a finite element analysis program SAPCAD is employed in this research. This program was designed by the research group of Tongji University, and it has been used to simulate the shaking table test, and provided a relatively precise result. ${ }^{4)-6}$. It could also be used to analyze the nonlinear behavior of beams, columns and whole structures.

\subsection{Finite element model}

In order to simulate the seismic behavior of the walls, a type of 4 node element is applied. Since the scattering reinforcement in the wall is nearly uniform, the concrete and the reinforcement could be considered as the continuous element. The concrete crack model is used as scattering crack model. It is assumed that the tension stress of certain point overpasses tension strength, the concrete in the normal direction of the

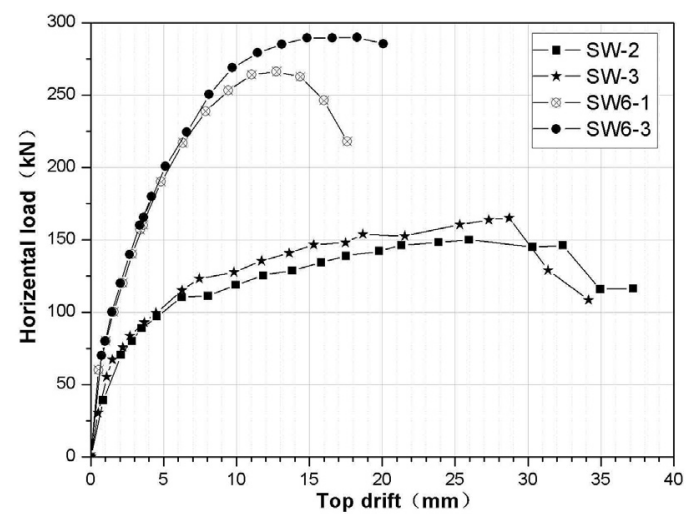

Fig.4. Skeleton Curve of the Specimens 


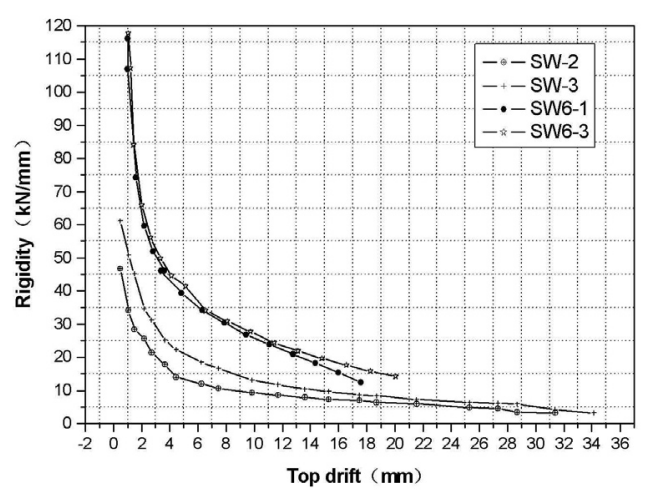

Fig.5. Rigidity Development Curve

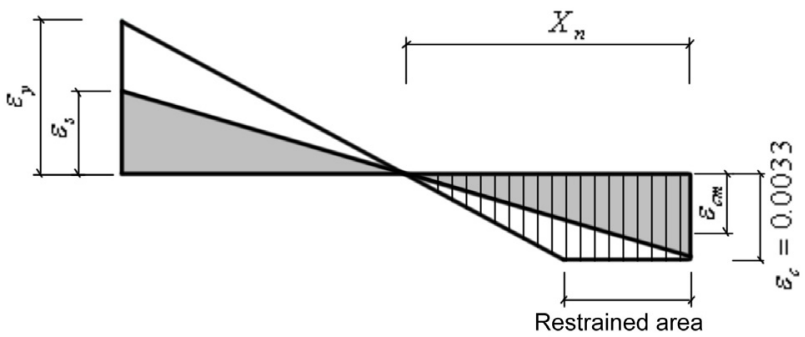

Fig.6. Strain Distribution of Typical Wall Section

point will crack. The concrete crack model is showed in Fig.7.

\subsection{Concrete material model}

This program supposes that the concrete is a kind of orthogonal anisotropy material, the stressstrain relationship is provided in Fig.8. The concrete constitutive relationship adopted the model provided by Saenz ${ }^{6}$. Other simulation analysis of the concrete walls mentioned in this paper use this model also gains rather good effects ${ }^{7}$.

The compression-ascending branch is defined by the equation below:

$$
\sigma_{i}=\frac{E_{0} \varepsilon_{i u}}{1+\left[\frac{E_{0}}{E_{s}}-2\right]\left(\frac{\varepsilon_{i u}}{\varepsilon_{i c}}\right)+\left(\frac{\varepsilon_{i u}}{\varepsilon_{i c}}\right)^{2}}
$$

Here:

$\sigma_{i}-$ principle stress;

$\varepsilon_{i u}-$ single axial equivalent strain;

$E_{0}$ - tangent module through initial point;

$E_{s}=\sigma_{i c} / \varepsilon_{i c}-$ secant module at the maximum stress.

The concrete tension stress is considered in the program which will be more close to the actual statue. The concrete stress-strain relationship in two directions is applied with the stress-strain increment relationship of the orthogonal anisotropy material.
The shear module after crack uses the relationship suggested by Al-Manaidi ${ }^{8)}$.

$$
G=\frac{0.4 G_{0}}{\varepsilon_{i} / \varepsilon_{t 0}}
$$

$G_{0}$ is the shear module before crack. $\varepsilon_{i}$ is the average tension strain and $\varepsilon_{t 0}$ is the tension strain at the crack moment, the shear rigidity is ignored when the two direction are both cracked.

\subsection{Concrete strength criterion}

Kupfer has provided a concrete criterion, which is also used in this program.

If the concrete is under pressure in two directions,

$$
\sigma_{2 c}=\frac{1+3.65 \alpha}{(1+\alpha)^{2}} f_{c} \quad 0 \leq \alpha=\sigma_{1} / \sigma_{2} \leq 1
$$

If the concrete is under pressure in one direction,

$$
\sigma_{1 t}=\left(1-0.8 \frac{\sigma_{2}}{f_{c}}\right) f_{t} \quad 0 \leq \alpha
$$

When the concrete are both in tension in two directions,

$$
\sigma_{1 t}=\sigma_{2 t}=f_{t}
$$

\subsection{Steel constitutive relationship}

The bilinear model is applied in the steel bars stress-strain relationship under cyclical loading. The modulus $E_{s}^{\prime}=0.01 E_{s 0}$ after steel bar yield $\left(E_{s 0}\right.$ is the initial modulus, $E_{s}^{\prime}$ is the post yielding modulus). Some steel bar constitutive relationship model have a harden stage, which depended on the steel material test.

Note that the steel bar in the concrete is considered as a continuous material in one dimension.

\section{Numerical Simulation}

\subsection{Simulation model}

In this investigation, the target walls are divided into 32 wall elements and 44 nodes. A beam element is set at the top to resist local deformation. The specimen model and the element division are shown in Fig.9. The load distribution and the deformation are also shown in Fig.9. The lateral load in the numerical simulation is fed according to the test procedure. The bottom of the model is totally fixed, and the top is considered as a free end.

In the modeling program, difference should be set in the boundary element of the four specimens. In order to specify the boundary element and the core wall, each model is organized by three parts. They are the core wall element (the inner two column elements in
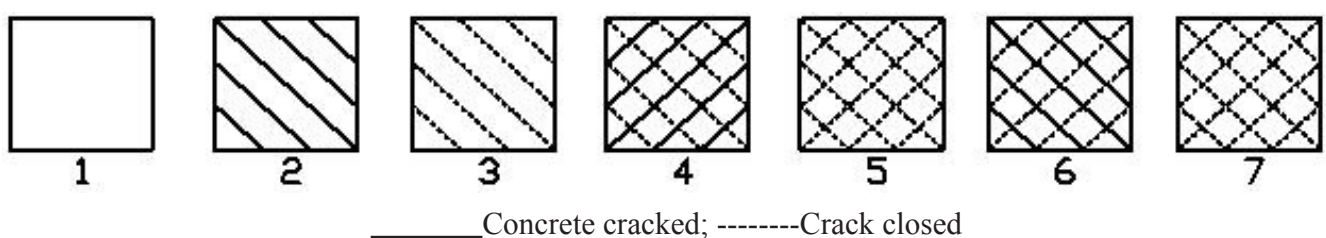

Concrete cracked; ---------Crack closed

Fig.7. Concrete Crack Mode 
Fig.9.) and boundary wall elements (outer two column elements in Fig.9.), and each part has a different reinforcement ratio. The outer two column element is considered as the main elements to resist the flexural moment, and the shear resist capacity is provided by the whole section.

Visual result could be provided by the program, including the deformation, the reinforcing bars and the concrete surface stress distribution. The wall element tension stress distribution diagrammatic sketch is shown in Fig.10., when the target wall is under the action of the lateral load.

\subsection{Analysis of experiment and simulation results}

Numerical simulations of the four specimens are conducted by the finite element program SAPCAD. Each specimen is fed with a cyclical lateral load and a constant vertical pressure. The simulation result and test result are compared in Fig.11.-14. The hysteretic curve of the four specimens including experimental curve and simulated curve are represented in each figure. It can be observed that the simulation result follows the experimental results well. The simulated hysteretic curves can precisely depict the outline of the test result. Asymmetric cyclic curve was detected from the test result of specimen SW-2 and SW-3, which may be caused by the defective test rig. The simulated loaddeformation relation curve matched the test result very well in the positive deformation area. The simulation result of specimen SW6-1 and SW6-3 could also agree with the test result, especial the outline of the curve and the ultimate bearing capacity. But both the simulation result of the two groups of specimens still could not come to good pinching and slipping effects which were detached in the experiment especially in the large displacement stage.

Experiment could found that the initial yield force and ultimate force of SW-3 is $9.4 \%$ and $10.6 \%$ higher than that of SW-2. The deformation ductility ratio appears has not apparent influent by the variety of the boundary stirrup. The simulation results provide the same evidence to these effects. The hysteretic hoop of SW-2 and SW-3 shaped as a reversed "S" (see Fig.15.) and there were apparent slip behavior when the specimen came close to failure. The hysteretic hoop and the crack scatter mode could give the evidence that specimen SW-2 and SW-3 is closer to shear failure mode, and the boundary stirrup effect is not so distinct.

The hysteretic hoop of SW6-1 and SW6-3 is shown in Fig.16. which shaped more like a spindle. The lateral bearing capacity of SW6-3 is higher than that of SW6-1 when they reached the same displacement. It could be judged that the specimen SW6-1 and SW6-3 show flexural failure mode considering the crack scattering mode, and the strengthening of boundary stirrup could enhance the bearing capacity and the deformation property. The simulation hoops could also give the evidence that the deformation resist capacity of SW6-3 is higher than that of SW6-1.
Comparing the two groups of specimens, SW6-1 and SW6-3 show more flexural property than that of SW-2 and SW-3. it could be observed from Table 5. that the longitudinal steel bars are more stronger than that of SW-2 and SW-3, and the aspect ratio is higher than that also. As a common belief, higher aspect ratio shear wall shows more flexure mode, and the strengthening of longitudinal bars may contribute to the bending capacity also.

Concrete walls with a boundary element may have a higher lateral bearing capacity when the failure mode shows flexure property. And the seismic energy dissipation capacity could not be influenced by the boundary stirrup apparently. The uncertainty of the drift ductility ratio may result in the definition of the ductility especially the yield point definition. Numerical simulation also has the same result. It needs to be mentioned that, there still exist differences between the simulation and the experimental results, which may be attributed to the difficulty in guarantying the actual analysis condition totally to the experimental condition. The actual experimental condition is influenced by loading equipments, the anchor style of the walls and the material cooperation property of the specimen. And the working condition may not totally the same, but the simulation model remains an idealized one.

The experiment and simulation analysis results in the investigation show that: (1) The program SAPCAD could provide rather precise simulation results of the reversed behavior of the shear wall especially the force-deformation skeleton and the ultimate bearing capacity; (2) the boundary element could enhance the lateral bearing capacity and the deformation capacity when the shear wall behaves as flexural mode, and the stirrup effect will not so apparent when it is closer to shear failure mode; (3) higher aspect ratio and stronger longitudinal steel bars in boundary area could contribute to the flexural failure mode.

The results as above mentioned are drawn only in this situation and the common conclusion still need more experiment and simulation evidence.

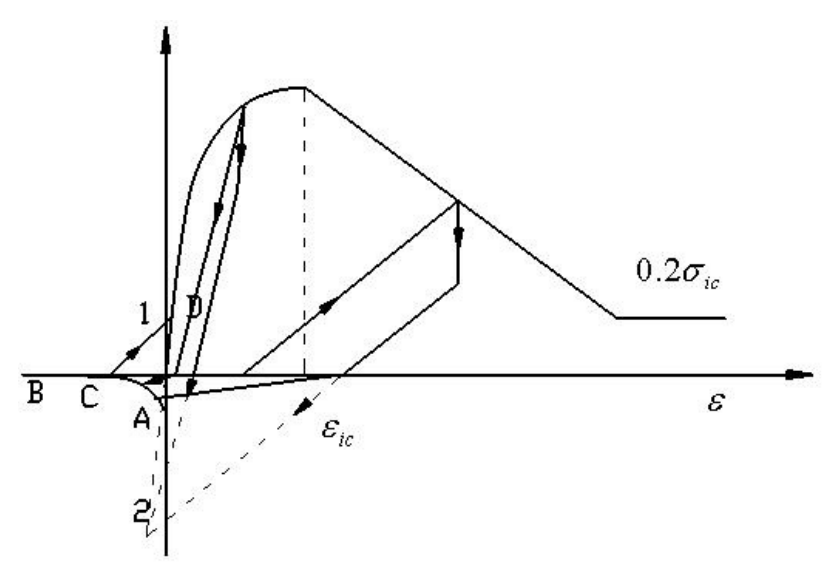

Fig.8. Concrete Constitutive Relationship 

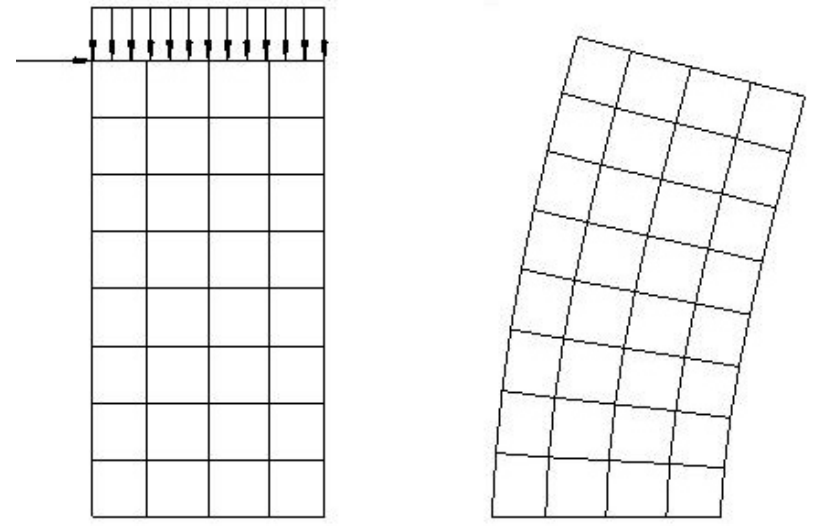

Fig.9. Model and Deformation Mode

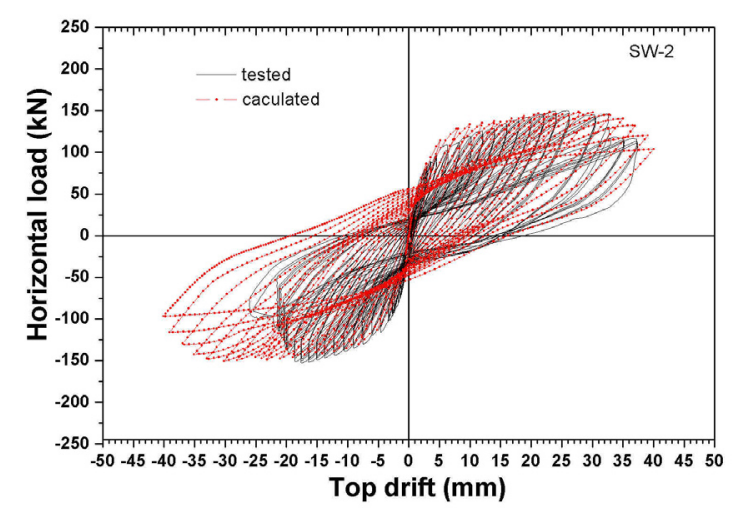

Fig.11. Tested and Simulated Hysteretic Curve of SW-2

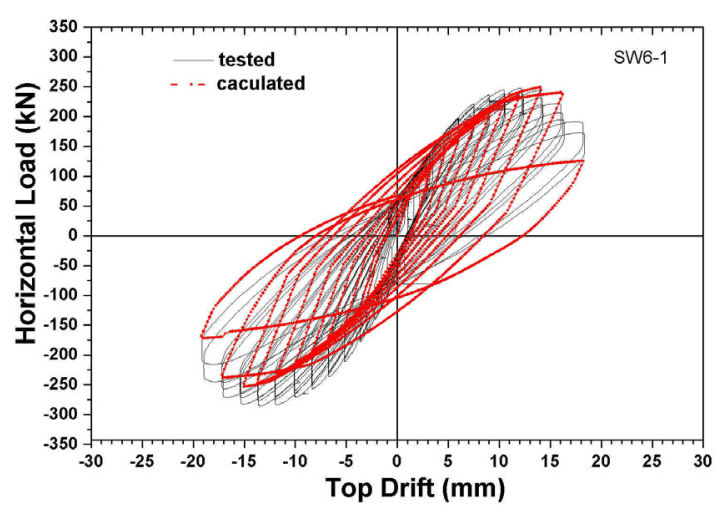

Fig.13. Tested and Simulated Hysteretic Curve of SW6-1

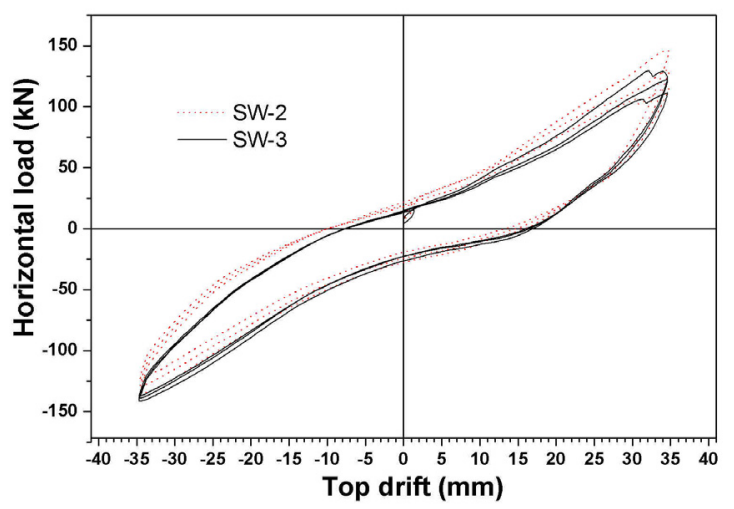

Fig.15. The Hysteretic Hoop of SW-2 and SW-3-the Maximum Displacement is $34 \mathrm{~mm}$

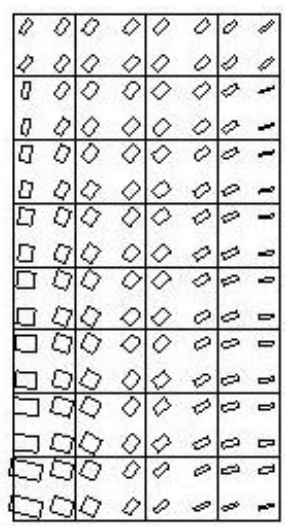

Fig.10. Tension Stress Distribution

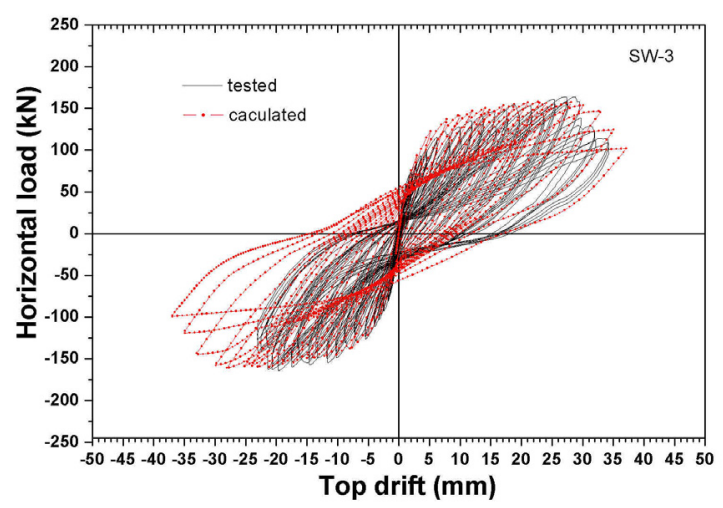

Fig.12. Tested and Simulated Hysteretic Curve of SW-3

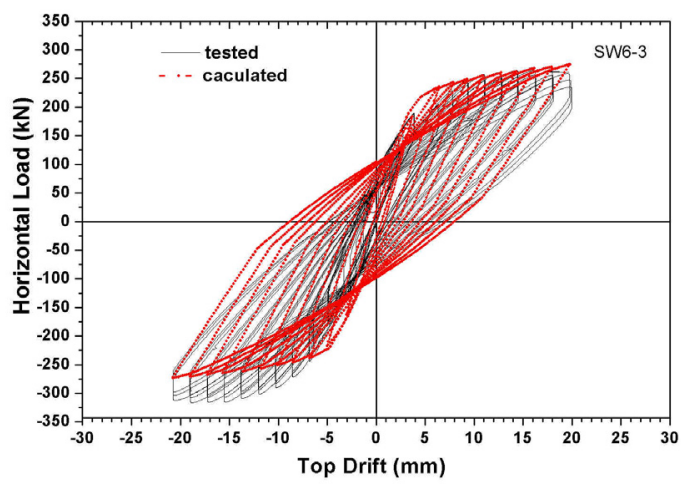

Fig.14. Tested and Simulated Hysteretic Curve of SW6-3

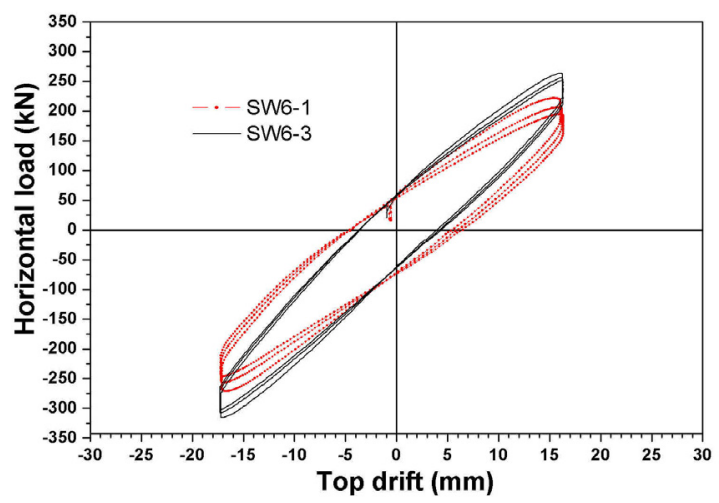

Fig.16. The Hysteretic Hoop of SW6-1 and SW6-3-the Maximum Displacement is $17 \mathrm{~mm}$ 


\section{Conclusions}

As has been stated, the reversed cyclic experiment of the shear walls provides the evidence to the boundary stirrup effect. The simulation research provides an efficient way to evaluate the seismic behavior of the shear walls with different stirrup ratio. Both the experiment and the simulation results come to the conclusion that:

(1) The finite element analysis program SAPCAD could provide rather precise simulation results by considering the boundary details, especially the ultimate lateral bearing capacity and the forcedeformation curve skeleton.

(2) Higher stirrup ratio is helpful to enhance the lateral rigidity, and is also contribute to make the rigidity degrading become gentler when the specimen is under a lateral force.

(3) Higher aspect ratio and stronger longitudinal steel bars in boundary area could contribute to the flexural failure mode.

(4) The strengthening of stirrup ratio in boundary area could enhance the lateral bearing capacity and the deformation resist capacity when the shear wall behaves as flexural mode, and the stirrup effect is not so apparent when it is closer to shear failure mode.

This research work could only provide some evidence to the above conclusion in the certain situation and the common conclusion still need more experiment and simulation evidence. The clarify of the boundary effect is helpful to the shear wall deformation control, and the simulation method considering the section detail will play an important role in the performance evaluation of the complex shear wall building.

\section{Acknowledgement}

The authors are grateful for the financial support of Kwang-Hua Fund for College of Civil Engineering, Tongji University, Shanghai Pujiang Program (Grant No. 08PJ1409900) and National Key Technology R\&D Program (Grant No. 2006BAJ13B01).

\section{References}

1) Loannis D. Lefas, M.D.K., Nicholas N.ambraseys, Behavior of Reinforced Concrete Structural Walls: Strength, Deformation Characteristics, and Mechanism. ACI Structural Journal, 1990. 87(1): 23-31.

2) Hongmei Zhang, Xilin Lu, Liang Lu, Wenqing Cao. The Influence of the Boundary Element on The Seismic Behavior of the Reinforced Concrete Shear Walls. Journal of Earthquake Engineering and Engineering Vibration, 2007. 27(1): 92-98.

3) Hongmei Zhang, Xilin Lu, Xueping Yang, Song Zhang. Influence of the Boundary Stirrup on the Seismic Behavior of Reinforced Concrete Shear Walls. Structural engineers, 2008. 24(5): 100-104.

4) Xilin Lu, Xiaohan Wu and Liang Meng, 1997, Seismic Behavior of A New Type of Seismic Energy Dissipation Shear Wall System, Structural Engineering and Mechanics, Vol.5, No.2, pp.167-175.

5) Xilin Lu and Xiaohan Wu, Study on a New Shear wall System with Shaking Table Test and Finite Element Analysis. Earthquake Engineering \& Structural Dynamics, 2000. 29(10): 1425-1440.

6) Xiaohan $\mathrm{Wu}$, Xilin $\mathrm{Lu}, \mathrm{A}$ Constitutive Model for Nonlinear F.E. Analysis of R.C. Shear Walls Under Cyclic Loading Proceedings of the Third Asian-Pacific Conference on Computational Mechanics, Volume 2: 1477-1482.

7) Saenz, L.P., Discussion of Equation for Stress-Strain Curve of Concrete by Desayi and Krishnan. Journal of ACI, 1964. 61(9): 1229-1235.

8) Makoto Maruta, N.S., Takashi Miyashita Structureal Capacities of H-Shaped RC Core Wall Subjected to Lateral Load and Torsion. 12WCEE. 2000. Auckland, New Zealand.

9) AL-Mahaidi, R.S.H., Nonlinear Finite Element Analysis of Reinforced Concrete Subjected to Shear Loading. Heron, 1981. 26(1a). 